\title{
Gestec como Ferramenta Estratégica para Transferência de Tecnologia de uma Instituição de Pesquisa Agropecuária: um estudo de caso na Embrapa Amapá
}

\author{
Gestec as a Strategic Tool for Technology Transference from an \\ Agricultural Research Institution: a case study at Embrapa Amapá
}

\author{
Adelina do Socorro Serrão Belém ${ }^{1}$ \\ Jesusa Vania Bagundes Nascimento ${ }^{2}$ \\ Claudio Márcio Campos de Mendonça ${ }^{2}$ \\ ${ }^{1}$ Embrapa Amapá, Macapá, AP, Brasil \\ ¿2Universidade Federal do Amapá, Macapá, AP, Brasil
}

\begin{abstract}
Resumo
Para que o processo de transferência de tecnologia ocorra de forma eficaz, os resultados das atividades realizadas pelas instituições públicas de pesquisa científica e tecnológica devem ser amplamente difundidos e compartilhados com o setor produtivo para que promovam múltiplos caminhos de socialização com a comunidade em geral. O objetivo deste trabalho é descrever a utilização e a contribuição estratégica do Sistema de Gerenciamento de Ativos Tecnológicos (Gestec) para as atividades de transferência de tecnologia executadas por uma instituição de pesquisa agropecuária no Amapá. Por meio de entrevista semiestruturada, buscou-se obter do responsável pelo Gestec os benefícios do uso da plataforma. O resultado demonstrou que o Gestec é uma importante ferramenta de apoio ao gerenciamento da pesquisa tecnológica, pois concentra os ativos tecnológicos da instituição e dos parceiros, colaborando para o processo de regularização das pesquisas e dos produtos desenvolvidos, garantindo maior agilidade na tomada de decisões e no acesso à informação.
\end{abstract}

Palavras-chave: Soluções Tecnológicas. Sistema de Informação. Transferência de Tecnologia.

\begin{abstract}
In order for the technology transference process to take place effectively, the results of activities carried out by public scientific and technological research institutions must be widely disseminated and shared with the productive sector in order to promote multiple paths of socialization with the community at large general. The objective of this paper is to describe the utilization and strategic contribution of the Technological Asset Management System (Gestec), to the technology transfer activities performed by an agricultural research institution in Amapá. Through semistructured interviews, we sought to obtain from the manager of Gestec, the benefits of using the platform. The result showed that Gestec is an important tool to support the management of technological research, as it concentrates the technological assets of the institution and partners, collaborating in the process of regularization of research and developed products, ensuring greater agility in decision making and access to information.
\end{abstract}

Keywords: Technological Solutions. Information System. Technology Transference.

Área Tecnológica: Propriedade Intelectual. Inovação e Desenvolvimento. 


\section{Introdução}

O termo inovação como fator explicativo dos ciclos econômicos surgiu a partir dos escritos de Schumpeter, no século XX, que, dentro do modelo capitalista no início da Revolução Industrial, elaborou a teoria do desenvolvimento econômico e diferenciou invenção de inovação. Invenção, como nova ideia, seria apenas um esboço ou modelo para um artefato, produto, processo ou sistema melhorado, já a inovação, no sentido econômico, somente é considerada completa quando há uma transação comercial envolvendo uma invenção e assim gerando riquezas (SCHUMPETER, 1988 apud AGUSTINHO; GARCIA, 2018).

Inovar é produzir novas tecnologias ou novas formas de realizar determinada atividade, que proporcionem maior facilidade, comodidade e economia às pessoas, empresas ou nações. Assim, a capacidade de produzir inovações vem sendo apontada como essencial para o desenvolvimento econômico e social, tanto em nível micro quanto macroeconômico. Existem muitas definições para o conceito de Inovação que vêm sendo ampliadas ao longo do tempo e das necessidades (MORGADO, 2011). Esse conceito é bastante variado, pois está relacionado com sua aplicação (AGUSTINHO; GARCIA, 2018).

É necessário inovar para responder às crescentes demandas por facilidade e comodidade, eficiência e qualidade, economia e lucratividade, nos mais diversos campos da vida social e empresarial, seja em nível individual, coletivo ou nacional. A inovação traz consigo a possibilidade de transformar a realidade. Uma instituição, região ou país que investe em inovação estará na vanguarda do crescimento econômico e social (AGUSTINHO; GARCIA, 2018; ROSA; ROSA; ANTONIOLLI, 2018).

A inovação somente se concretiza quando ocorre a transferência de tecnologia, ou seja, quando a nova tecnologia é inserida e aceita pela sociedade ou grupo social a qual é destinada. A Transferência de Tecnologia está diretamente relacionada à inovação, na medida em que esta só existe quando aquela é concretizada (ANDRADE et al., 2018; ARAÚJO et al., 2010).

Em outras palavras, a transferência de tecnologia se consolida mediante negociação comercial em que o titular da tecnologia permite o acesso de outrem aos conhecimentos tecnológicos, mediante compensação financeira. Desse modo, a formalização da transação comercial deve ser realizada por meio de contratos de transferência de tecnologia.

Assim, a inovação, em particular a inovação tecnológica, considerada no contexto contemporâneo como essencial e estratégica na diferenciação, competitividade e desenvolvimento no mundo empresarial, chega ao setor produtivo por meio da transferência de tecnologia, efetivada pela celebração de contratos de transferência de tecnologia e contratos de licenciamento (FUCK; VILHA, 2012).

No Brasil, promover o desenvolvimento científico e tecnológico é uma obrigação do Estado prevista na Constituição Federal do país (BRASIL, 1988). Ao longo dos anos, um arcabouço legal foi sendo criado buscando esse fim, e uma importante conquista foi alcançada com a promulgação da Lei de Inovação - Lei n. 10.973, também conhecida como Marco Legal da Inovação - que estabeleceu medidas de "[...] incentivos à inovação e à pesquisa científica e tecnológica no ambiente produtivo" (BRASIL, 2004). Mais recentemente, o Novo Marco Legal - Lei n. 13.243 (BRASIL, 2016a) ampliou as medidas de incentivo à inovação, alterando leis anteriores, abordando novos conceitos do ambiente produtivo e prevendo a parceria entre 
instituições públicas e privadas, com o propósito de estimular a inovação no país e favorecer a transferência de tecnologia.

A gestão da inovação envolve, além do incentivo à invenção, ou seja, ao desenvolvimento ou melhoramento de novos produtos, processos e métodos, a proteção da propriedade intelectual e a transferência do conhecimento ou tecnologia ao setor produtivo para que chegue a sociedade (BOZEMAN, 2000).

A produção técnico-científica brasileira concentra-se principalmente nas universidades e nos centros de pesquisa públicos. Por essa razão, devem existir mecanismos adequados para a gestão da propriedade intelectual, a fim de facilitar os processos de proteção, transferência $e$ divulgação das tecnologias geradas nas instituições.

Nessa direção, a Empresa Brasileira de Pesquisa Agropecuária (Embrapa) desenvolveu e implementou o Sistema de Gerenciamento de Ativos Tecnológicos (Gestec), uma plataforma digital voltada ao gerenciamento dos ativos tecnológicos de cada Unidade da instituição, de modo a proporcionar o atendimento ágil e seguro dos instrumentos exigidos para difusão das atividades de pesquisas tecnológicas executadas internamente ou em parceria.

O estudo do gerenciamento do acervo dos ativos tecnológicos é importante para conhecer como as ICTs fazem essa governança e a posterior disponibilidade para a sociedade, como preconiza o Decreto n. 9.273, de 7 de fevereiro de 2018 que regulamenta a Lei de Inovação e Marco Legal de CT\&I e que prevê a publicação de extratos em sítio eletrônico oficial da Instituição (BRASIL, 2018).

Nesse contexto, o objetivo deste trabalho é descrever a utilização e a contribuição estratégica do Gestec para as atividades de transferência de tecnologia executadas pela Unidade Descentralizada da Embrapa no Amapá.

\section{Metodologia}

Esta pesquisa caracteriza-se como um estudo exploratório e descritivo na forma de um estudo de caso, apresentando uma abordagem qualitativa. O estudo de caso foi realizado em uma das unidades descentralizadas da Embrapa, a Embrapa Amapá, localizada em Macapá, Amapá, Brasil. O principal objetivo deste estudo foi descrever a utilização e a contribuição estratégica do Sistema de Gerenciamento de Ativos Tecnológicos (Gestec) para as atividades de transferência de tecnologia, executadas pela Embrapa Amapá.

A coleta de dados foi realizada por meio de análise documental e entrevistas semiestruturadas com dois dos três profissionais responsáveis pela alimentação do sistema na Unidade: o Engenheiro-agrônomo, doutor, pesquisador e atual Chefe-Adjunto de Transferência de Tecnologia da Embrapa Amapá; e o Zootecnista, mestre em Zootecnia, Analista A na área de Transferência de Tecnologias, do Setor de Prospecção e Avaliação de Tecnologias (SPAT). O SPAT é o setor responsável pelo gerenciamento do Gestec nas Unidades da Embrapa.

As entrevistas semiestruturadas foram realizadas a partir de um pré-questionário elaborado pelos autores, contendo cinco questões abertas sobre a utilização do Gestec pela Embrapa Amapá no intuito de obter informações e opiniões dos profissionais responsável pelo sistema.

A análise documental foi realizada com base nos manuais internos sobre o Sistema Gestec, disponibilizados pela Embrapa Amapá, e pelos conteúdos relacionados ao tema disponibilizados 
no site da Embrapa Amapá. Na análise das respostas obtidas nas entrevistas foi utilizada a metodologia de análise de conteúdo (os Quadros 1 e 2). Foram observadas ainda as disposições legais relacionadas à transferência de tecnologia, refletindo sobre aspectos como as alterações da regulamentação e as consequências para as pesquisas envolvendo transferência de tecnologia.

Trata-se de uma pesquisa exploratória, uma vez que, segundo Marconi e Lakatos (2003), analisa-se determinado tema com finalidade de desenvolver hipóteses e de aumentar a familiaridade do pesquisador com um ambiente, fato ou fenômeno para clarificar conceitos. Como reforçado por Gil (2002), o entendimento desse tipo de pesquisa é proporcionar maior familiaridade com o problema, com vistas a torná-lo mais explícito ou a constituir hipóteses, de forma que se pudesse dizer que tem como objetivo principal o aprimoramento de ideias ou a descoberta de intuições.

O trabalho é um estudo de caso único, pois, segundo Yin (2001), trata-se de uma inquirição empírica que investiga um fenômeno contemporâneo dentro de seu contexto real, especialmente quando os limites entre fenômeno e contexto não estão claramente evidentes, sendo assim, deve-se escolher, entre as modalidades de estratégias qualitativas, a de estudo de caso para realização da pesquisa.

A abordagem descritiva-qualitativa foi adotada na intenção de explicitar as características específicas do objeto pesquisado, visando a melhor compreensão do funcionamento do Gestec. Os procedimentos adotados adequam-se a pesquisa de natureza qualitativa, conforme descrito por Gil (2002).

A partir da análise dos dados obtidos, foi possível identificar as principais características do Gestec e como o sistema contribui para a Gestão da Propriedade Intelectual e Transferência de Tecnologia na Embrapa Amapá. Convém destacar que, por se tratar de um estudo de caso, a pesquisa apresenta limitações, especialmente decorrentes das condições específicas da Unidade analisada, não sendo recomendado que sejam realizadas generalizações de seus resultados.

\section{Resultados e Discussão}

A propriedade intelectual é a criação resultante da capacidade inventiva da mente humana e pode ser protegida de acordo com três categorias: Direito de Autor, Propriedade Industrial e Direito Sui Generis. Todas conferem direitos ao autor/inventor da obra/tecnologia por determinado período, visando compensar o esforço despendido na criação. Por outro lado, para obter a proteção, o autor permite a publicação do conhecimento adquirido. O objetivo é que o conhecimento seja compartilhado para que outros pesquisadores tenham acesso e possam desenvolver novas pesquisas, elevando gradativamente a capacidade inovativa do país. Assim ocorre a difusão de novos conhecimentos que alteram o estado da arte, ou seja, o que é de conhecimento público, contribuindo para aumentar o nível de desenvolvimento científico, tecnológico e, por conseguinte, a capacidade competitiva do país (ARAÚJO et al., 2010).

Uma vez protegida, o passo seguinte é a transferência da tecnologia propriamente dita entre indivíduos ou organizações, mediante acordo entre o titular da tecnologia e a parte interessada em utilizá-la ou em explorá-la (SOUZA; RODRIGUES, 2016). Simplificadamente, trata-se de uma ação de troca relacionada à tecnologia desenvolvida, na qual o titular da tecnologia permite o 
acesso da parte interessada ao conhecimento técnico sensível e, em contrapartida, recebe, em geral, ganhos econômicos (BOZEMAN, 2000).

Conforme aponta Ribeiro (2001, p. 15):

Em linhas gerais, a expressão Transferência de Tecnologia significa uma transferência formal de novas descobertas e/ou inovações resultantes de pesquisa científica administrada pelas instituições de pesquisa ou empresas para o setor industrial e comercial. Patentear e autorizar o uso das inovações é uma forma de as instituições de pesquisa transferirem tecnologia pronta.

No Brasil, as pesquisas básica e aplicada ainda estão concentradas no ambiente acadêmico: universidades e institutos tecnológicos, relevando a grande importância dessas instituições na produção e transferência de tecnologias (FERNANDES et al., 2018). As indústrias brasileiras, com algumas exceções, pouco investem em pesquisa e desenvolvimento, sendo esse um fator que contribui para o desempenho pouco satisfatório do Brasil no cenário internacional (CAMPOS; CALLEFI; MARCON, 2009).

A capacidade de inovação das empresas brasileiras, bem como a produção do conhecimento técnico-científico nas universidades e, ainda, a integração entre os diversos atores do sistema de inovação são elementos essenciais para o contínuo amadurecimento do processo de inovação no Brasil. Além disso, há o aperfeiçoamento dos mecanismos de proteção e transferência de tecnologia para se obter melhores resultados (ROMAN; LOPES, 2012).

A Empresa Brasileira de Pesquisa Agropecuária (Embrapa) vem há 46 anos trilhando esse caminho e, na condição de instituição governamental dedicada à pesquisa agropecuária, busca continuamente se ajustar aos novos tempos, trazidos por leis recentes relacionadas ao trabalho em ciência, tecnologia e inovação (EMBRAPA, 2018) e tem como visão ser referência mundial na geração e oferta de informações, conhecimentos e tecnologias, contribuindo para a inovação e a sustentabilidade da agricultura e segurança alimentar (EMBRAPA, 2019).

A Embrapa tem desenvolvido, aprimorado e aplicado estratégias e ferramentas para tornar-se mais responsiva, demonstrando, simultaneamente, seus esforços para estar cada vez mais alinhada aos interesses públicos (MANOS et al., 2018), pois o setor agrícola vivencia transformações relevantes em razão da migração da sociedade da informação e do conhecimento para a sociedade da era digital (EMBRAPA, 2018). Nesse sentido, a Embrapa empenha esforços na transformação digital da agricultura brasileira desde a década de 1990, já que ela, com o advento da internet, vem organizando e disponibilizando sua informação técnico-científica via web (SANTOS et al., 2018).

Para o gerenciamento das informações dos ativos tecnológicos produzidos pela Empresa, foi desenvolvido pela equipe técnica da Embrapa Informática Agropecuária (Campinas, SP) e implantado na Embrapa em março de 2014, o Sistema de Gestão dos Ativos Tecnológicos (Gestec). Desde então, a equipe do Departamento de Transferência de Tecnologia da Embrapa (DTT), localizada em Brasília, DF, e as equipes das áreas de TT das Unidades Descentralizadas trabalham na inserção e na atualização das informações no sistema.

O objetivo principal desse sistema é o cadastramento e a manutenção do acervo de ativos tecnológicos produzidos pela Embrapa e em parceria com outras instituições. Além disso, o sistema automatiza as etapas do Processo de Qualificação dos Ativos oriundos dos projetos de 
pesquisa da Embrapa (TURAZI et al., 2018). Assim, o Gestec tornou possível a categorização e a disponibilização de todas as soluções tecnológicas da Embrapa, permitindo a geração de relatórios e o gerenciamento das informações pelas respectivas unidades.

O Gestec é acessado por meio da Intranet da Embrapa e restrito aos empregados cadastrados. Cada Unidade da Embrapa é responsável por cadastrar e manter atualizadas as informações sobre suas soluções tecnológicas. O sistema está baseado na organização das soluções tecnológicas por tipo e pelas respectivas categorias/formas de entrega. Utiliza a Escala TRL/ MRL, escala desenvolvida pela Nasa e utilizada para avaliar uma tecnologia ou um processo $e$ enquadrá-los em Níveis de Maturidade Tecnológica. Essa escala proporciona um mecanismo de acompanhamento do processo de pesquisa, desenvolvimento e de validação, ao mesmo tempo em que permite a comparação direta entre diferentes.

É um sistema corporativo e tem integração automática com outros sistemas da Empresa como Sistema de Pessoa Jurídica; Sistema de Recursos Humanos; Cadastro de Softwares; IDEARE (Sistema de Gerenciamento da Programação da Embrapa); Cadastro de licenciados mantidos pela Embrapa Produtos e Mercados (Sistema de Gestão de Contratos - SGC) e Portal da Embrapa.

Entre suas principais funcionalidades, o Gestec fornece tabelas das soluções tecnológicas quanto ao tipo ou categoria, tema ou público-alvo para transferência de tecnologia, as quais somente podem ser acessadas pelo DTT; o Gerenciamento das Soluções Tecnológicas, da Embrapa e de outras instituições, que pode ser realizado pelos agentes de TT; e os relatórios gerados pelo sistema, que são acessíveis a todos os cadastrados. As soluções tecnológicas validadas pelo Gestec compõem o portfólio digital da Embrapa, disponível no Portal da instituição e acessível ao público geral.

Portanto, trata-se de um Sistema fundamental no apoio à tomada de decisão para a Empresa, que entre muitos levantamentos, apresentou em fevereiro de 2016, as soluções tecnológicas disponíveis no Portal da Embrapa e evolução das soluções tecnológicas no período de 1996 a 2014. Possibilita a concretização do processo de TT com relação aos ativos tecnológicos (SILVA NETTO; OLIVEIRA, 2014), e a adoção pelo usuário final, pois, segundo Cavalcanti (2015), transferência de tecnologia compreendida como processo, apenas se completa com a efetiva adoção da tecnologia pelo seu usuário.

\subsection{Gerenciamento dos Ativos Tecnológicos: o caso da Embrapa Amapá}

Este estudo de caso foi realizado na Embrapa Amapá, uma das 42 Unidades Descentralizadas da Empresa Brasileira de Pesquisa Agropecuária (Embrapa), vinculada ao Ministério da Agricultura, Pecuária e Abastecimento (MAPA). Localizada em Macapá, Amapá, Brasil, a Embrapa Amapá foi criada em 1980 como Núcleo de Pesquisa Agropecuária do Amapá com o objetivo de desenvolver tecnologias para a "sustentabilidade da agricultura e do uso da biodiversidade na Amazônia, com ênfase no estado do Amapá e estuário amazônico". Atualmente conta com uma estrutura de: dois auditórios, duas salas de reuniões, uma biblioteca, 20 laboratórios, um galpão de cultivo de organismos aquáticos e recepção de amostras de solos, um galpão de gerenciamento de resíduos laboratoriais, um galpão de resíduos sólidos, um galpão de transportes, três campos experimentais, uma área de convivência, além de salas de administrativas e de pesquisa. Atua em cinco núcleos temáticos: Aquicultura e Pesca; Conservação e Uso dos 
Recursos da Biodiversidade; Proteção de Plantas; Recursos Florestais; Sistemas Sustentáveis de Produção Agropecuária.

A gestão dos ativos tecnológicos desenvolvidos na Embrapa Amapá é realizada por meio do Gestec, que, por sua vez, é gerenciado pelo Setor de Prospecção e Avaliação de Tecnologias (SPAT). O resultado das entrevistas realizadas é apresentado no Quadro 1.

Quadro 1 - Perguntas e respostas sobre o Gestec na Embrapa Amapá

\begin{tabular}{|c|c|c|}
\hline Perguntas & PARTICIPANTE 1 & PARTICIPANTE 2 \\
\hline $\begin{array}{c}\text { 1. Quais as } \\
\text { contribuições do } \\
\text { Gestec para a } \\
\text { TT na Embrapa } \\
\text { Amapá? }\end{array}$ & $\begin{array}{c}\text { - O Gestec é um Sistema para Gestão } \\
\text { das Soluções Tecnológicas da Embrapa e } \\
\text { parceiros. Essa ferramenta permite ao usuário } \\
\text { acompanhar o desenvolvimento de um ativo } \\
\text { tecnológico durante todo o seu processo } \\
\text { de maturação. Esse acompanhamento é } \\
\text { feito por meio do monitoramento dos níveis } \\
\text { ascendentes de maturidade tecnológica } \\
\text { conhecidos como TRL/MRL. No que diz } \\
\text { respeito às contribuições do Gestec para a TT } \\
\text { da Embrapa Amapá, podemos afirmar que } \\
\text { essa ferramenta permitiu a sistematização } \\
\text { do acompanhamento de nossos diferentes } \\
\text { ativos tecnológicos em escala temporal, } \\
\text { fazendo com que os esforços da equipe para } \\
\text { finalização de um ativo sejam convergentes. } \\
\text { Apresenta um módulo para participação do } \\
\text { Comitê Local de Propriedade Intelectual (CLPI) } \\
\text { da Embrapa. Nesse módulo o CLPI se manifesta, } \\
\text { por meio de um parecer, quanto a pertinência } \\
\text { ou não da proteção daquele ativo tecnológico } \\
\text { que está sendo analisado. Além disso, um } \\
\text { módulo referente ao Acesso ao Patrimônio } \\
\text { Genético e Conhecimento Tradicional Associado } \\
\text { também é contemplado pelo Gestec. }\end{array}$ & $\begin{array}{l} \\
\text { - Processo essencial para promover } \\
\text { a transferência de tecnologias, } \\
\text { inserção no mercado de ativos } \\
\text { tecnológicos da Embrapa Amapá e } \\
\text { disponibilização para a sociedade. } \\
\text { - Apoio na qualificação dos projetos } \\
\text { de pesquisa, através da seleção de } \\
\text { resultados que passarão por processo } \\
\text { de identificação, caracterização e } \\
\text { qualificação de ativos tecnológicos. } \\
\text { - Gerenciamento de portfólios de ativos } \\
\text { e a manutenção das informações sobre } \\
\text { os ativos gerados e em desenvolvimento } \\
\text { pela Embrapa Amapá e em parceria } \\
\text { com outras instituições do Estado. }\end{array}$ \\
\hline $\begin{array}{l}\text { 2. Quais os } \\
\text { desafios na } \\
\text { utilização interna } \\
\text { do Gestec? }\end{array}$ & $\begin{array}{l}\text { - Os principais desafios estão relacionados } \\
\text { à integração das equipes de P\&D e TT para } \\
\text { priorização e qualificação dos ativos. Essa } \\
\text { integração ainda é deficiente e isso dificulta } \\
\text { a evolução da qualificação e finalização de } \\
\text { ativos pesquisados pela Embrapa Amapá. } \\
\text { Na verdade, a filosofia do Gestec é integrar os } \\
\text { esforços das diferentes equipes envolvidas no } \\
\text { desenvolvimento de um ativo tecnológico, ou } \\
\text { seja, fazer com que as ações produzam PD\&I. }\end{array}$ & $\begin{array}{l}\text { - Clareza no entendimento do } \\
\text { objetivo e função da ferramenta } \\
\text { para posicionamento correto do } \\
\text { ativo tecnológico no mercado. } \\
\text { - Apoio da Chefia de P\&D e TT } \\
\text { na implementação do processo de } \\
\text { qualificação, para que seja utilizado } \\
\text { como rotina da Unidade criando a } \\
\text { Cultura da Inovação da Embrapa. } \\
\text { - Interação entre sistemas corporativos } \\
\text { (Ideare, Quaesta) e interação } \\
\text { colaborativa entre Comitês Internos } \\
\text { (CGEN, CEUA, CLPI, CTI). }\end{array}$ \\
\hline $\begin{array}{l}\text { 3. Quais os } \\
\text { melhoramentos } \\
\text { que poderiam } \\
\text { facilitar a } \\
\text { utilização da } \\
\text { ferramenta? }\end{array}$ & $\begin{array}{l}\text { - A ferramenta é muito útil e integra todos os } \\
\text { segmentos envolvidos no desenvolvimento } \\
\text { de um ativo tecnológico na Embrapa. }\end{array}$ & $\begin{array}{c}\text { - Promover treinamentos (capacitação) no } \\
\text { entendimento do processo de qualificação } \\
\text { do ativo pelos agentes de TT e CTI. }\end{array}$ \\
\hline
\end{tabular}


4. Quais ações foram e/são utilizadas para divulgação da ferramenta tanto internamente como externamente?
- A divulgação do Gestec é realizado somente em nível interno na Embrapa. Isso não quer dizer que ativos de parceiros externos não sejam priorizados, somente as ações de divulgação e operacionalização é que são realizadas em nível interno.
- Em 2018, foi realizada a implantação do processo de qualificação dos ativos na Unidade pela Chefia de TT.

- Utilizada e considerada na Avaliação Institucional da Unidade junto a

SDI (Secretaria de Desenvolvimento Institucional) para compor o Balanço Social da Embrapa.

\section{Se}

precisássemos de um levantamento das tecnologias da Embrapa Amapá nos últimos cinco anos, ele poderia ajudar?

Se sim, como poderíamos obter?
- Sim. O Sistema permite a busca por ativos tecnológicos de anos anteriores. Além disso, o Sistema também permite a busca por tipo de ativo e se o ativo de interesse já está aprovado para utilização pelo mercado ou não.
- A ferramenta permite gerar relatórios das tecnologias qualificadas e em qualificação pela Unidade, por tipo, categoria e ano do ativo tecnológico.

- É uma ferramenta corporativa utilizada por todas as Unidades da Empresa e permite o acesso ao acervo de ativos desenvolvidos pela Embrapa em diversos estágios de maturidade da Escala TRL/ MRL. Além disso, é fonte das informações que alimentam o Portal da Embrapa.

Fonte: Elaborado pelos autores deste artigo

Com base nas respostas obtidas foi possível inferir que o Gestec é uma importante ferramenta de apoio à pesquisa tecnológica na Embrapa Amapá, uma vez que se configura fundamental no processo de regularização dos ativos tecnológicos das pesquisas realizadas na Embrapa $e$ em parceria, e colabora com um planejamento de TT mais eficiente com vistas à exploração de oportunidades e difusão de ativos tecnológicos da Unidade.

A escala de níveis de maturidade tecnológica - TRL/MRL é amplamente utilizada por institutos de pesquisa, universidades, agências de fomento, órgãos de governo, empresas e indústrias nacionais e internacionais (CAPDEVILLE et al., 2017) e seu uso no Gestec constitui-se um facilitador na avaliação das tecnologias cadastradas.

A possibilidade de manifestação do Comitê Local de Propriedade Intelectual (CLPI) dentro do Gestec para emitir parecer quanto à pertinência ou não da proteção de determinado ativo tecnológico que esteja sendo analisado, contribui para maior agilidade no andamento dos processos avaliativos.

Da mesma forma, o Módulo referente ao Acesso ao Patrimônio Genético e Conhecimento Tradicional Associado também é contemplado pelo Sistema, considerando o novo marco legal da biodiversidade no País, estabelecido por meio da Lei n. 13.123, de 20 de maio de 2015 (BRASIL, 2015) e pelo Decreto n. 8.772, de 11 de maio de 2016 (BRASIL, 2016b).

Como desafios enfrentados para melhor desempenho do Gestec na Embrapa Amapá, os participantes apontaram a necessidade de maior integração entre as equipes de P\&D e TT para priorização e qualificação dos ativos. 
Na fala de Cavalcanti (2015), percebe-se que o processo de efetivação da Transferência de Tecnologia na Embrapa é recente, o que pode dificultar maior integração entre os atores de P\&D e TT. Conforme reforçado por Bassi e Silva (2014, p. 371):

Sugere-se assim, que haja uma maior participação da equipe de TT na definição das estratégias e instrumentos a serem utilizados para transferir a tecnologia gerada, pois entende-se que essa participação poderá contribuir de forma decisiva para o correto estabelecimento das estratégias e instrumentos para a transferência de tecnologia.

As respostas a sugestão de melhoria relacionam-se também aos desafios enfrentados, ou seja, viabilidade de treinamentos (capacitação) para melhor engajamento dos atores envolvidos no processo de qualificação dos ativos pelos agentes de TT e CTI.

Quanto à divulgação do Gestec na Embrapa Amapá, por ser um sistema de uso interno, a divulgação ocorre internamente. Conforme informado por um dos participantes, no ano de 2018, foi realizada a implantação do processo de qualificação dos ativos da Embrapa Amapá pela Chefia de TT e foi utilizada e considerada na Avaliação Institucional da Unidade junto a Secretaria de Desenvolvimento Institucional (SDI) para compor o Balanço Social da Empresa, fato que colabora para disseminar o uso e importância do Gestec entre os funcionários da Unidade.

A divulgação externa ocorre por meio dos resultados apresentados, ou seja, os ativos, depois de cadastrados, avaliados e aprovados, são disponibilizados no catálogo da instituição que fica acessível para consulta não somente dos clientes da Embrapa Amapá como também de toda a sociedade. Os ativos de parceiros externos são igualmente priorizados, conforme reforçado por Turazi et al. (2018) no objetivo do Sistema.

Como reforçado pelos participantes, a ferramenta permite ainda a geração de relatórios das tecnologias qualificadas e em qualificação pela Embrapa Amapá por tipo, categoria e ano do ativo tecnológico, oferecendo um banco de dados ágil e completo que torna mais eficiente a gestão dos ativos tecnológicos da Unidade.

\section{Considerações Finais}

O estudo permitiu o conhecimento das funcionalidades do Gestec e sua utilização na Unidade da Embrapa Amapá, demonstrando a importância do sistema como ferramenta estratégica para o desenvolvimento das atividades de transferência de tecnologia, pois possibilita o cadastro e acompanhamento dos ativos tecnológicos desenvolvidos pela instituição.

O Gestec organiza as soluções tecnológicas em categorias e permite a geração de relatórios específicos facilitando o acesso às informações, seja em nível nacional ou local. Trabalha com integração a diversos outros sistemas oportunizando o cruzamento de informações, e assim, direcionando ações necessárias para validação de soluções tecnológicas e tomada de decisões.

Outra função importante da plataforma é a automatização do Processo de Qualificação dos Ativos resultantes das pesquisas da Embrapa, que fornece informações atualizadas do nível de maturidade, ou seja, da etapa de desenvolvimento de cada tecnologia, permitindo à empresa avaliar as necessidades de proteção e possibilidades de transferência antes mesmo que a tecnologia esteja pronta. Além disso, permite ainda manifestação do Comitê Local de Propriedade Intelectual (CLPI), quanto à pertinência ou não da proteção de determinado ativo tecnológico. 
Cabe ao Setor de Prospecção e Avaliação de Tecnologias de cada Unidade da Embrapa alimentar o sistema com informações atualizadas de suas soluções tecnológicas, o que significa que o sucesso da plataforma é resultado da conjugação de esforços de todos os responsáveis por tal atribuição. Assim, é fundamental que as equipes estejam capacitadas e em número adequado de agentes, favorecendo a constante manutenção e atualização do acervo de ativos tecnológicos do sistema.

No caso específico da Embrapa Amapá, o Gestec oportuniza maior visibilidade dos ativos desenvolvidos na Unidade, possibilitando maior alcance dos resultados. Desse modo, o Gestec proporciona integração com outras unidades e oferece um panorama do que está sendo produzido em cada unidade da Embrapa.

A experiência da Embrapa Amapá com o uso do Gestec mostra-se extremamente positiva, apesar da necessidade de maior sensibilização de todos os atores envolvidos para o funcionamento adequado do sistema.

O uso do sistema por outras unidades da Embrapa abre a possibilidade de expandir a análise, em estudos futuros, para uma avaliação mais eficiente da ferramenta para a gestão da propriedade intelectual produzida na instituição, imprescindível e estratégica para o acompanhamento e qualificação dos ativos tecnológicos, garantindo maior agilidade e segurança na tomada de decisões relacionadas à proteção dos ativos e às atividades de transferência de tecnologia.

\section{Referências}

AGUSTINHO, E.; GARCIA, E. Inovação, transferência de tecnologia e cooperação. Direito e Desenvolvimento, [S.l.], v. 9, n. 1, p. 223-239, jan.-jul. 2018. Disponível em: https://periodicos. unipe.br/index.php/direitoedesenvolvimento/article/view/525/512. Acesso em: 6 jul. 2019.

ANDRADE, H. de S. et al. Transferência de Tecnologia: uma discussão sobre os fatores críticos de sucesso para os transmissores e para os receptores da tecnologia. Revista Espacios, [S.1.], v. 39, n. 9, 2018. Disponível em: http://www.revistaespacios.com/a18v39n09/a18v39n09p01.pdf. Acesso em: 6 jul. 2019.

ARAÚJO, E. F. et al. Propriedade Intelectual: proteção e gestão estratégica do conhecimento. Revista Brasileira de Zootecnia, [S.l.], Suplemento Especial, v. 39, p. 1-10, jul. 2010. Disponível em: http://www.scielo.br/scielo.php?script=sci_arttext\&pid=S1516-35982010001300001. Acesso em: 5 jul. 2019.

BASSI, N. S. S.; SILVA, C. da S. As estratégias de divulgação científica e transferência de tecnologia utilizada pela Empresa Brasileira de Pesquisa Agropecuária (Embrapa). Interações, [S.I.], v. 15, n. 2, p. 361-372, 2014. Disponível: http://ainfo.cnptia.embrapa.br/digital/bitstream/item/114216/1/ final7774.pdf. Acesso em: 10 jul. 2019.

BOZEMAN, B. Technology transfer and public policy: a review of research and theory. Research Policy, [S.1.], v. 29, n. 4-5, p. 627-655, Apr. 2000. Disponível em: https:/www.sciencedirect.com/ science/article/abs/pii/S0048733399000931. Acesso em: 17 jul. 2019.

BRASIL. Constituição da República Federativa do Brasil. Promulgada em 5 de outubro de 1988.

Diário Oficial (da) República Federativa do Brasil, Brasília, DF, 5 out. 1988. Disponível em: http://www.planalto.gov.br/ccivil_03/Constituicao/Constituicao.htm. Acesso em: 6 jul. 2019. 
BRASIL. Lei n. 10.973, de 2 de dezembro de 2004. Dispõe sobre incentivos à inovação e à pesquisa científica e tecnológica no ambiente produtivo e dá outras providências. Diário Oficial (da)

República Federativa do Brasil, Brasília, DF, 2 dez. 2004. Disponível em: http://www.planalto.gov. br/ccivil_03/_ato2004-2006/2004/lei/110.973.htm. Acesso em: 5 jul. 2019.

BRASIL. Lei n. 13.123, de 20 de maio de 2015. Disponível em: http://www.planalto.gov.br/ ccivil_03/_ato2015-2018/2015/lei/113123.htm. Acesso em: 9 mar. 2020.

BRASIL. Lei n. 13.243, de 11 de janeiro de 2016. Dispõe sobre estímulos ao desenvolvimento científico, à pesquisa, à capacitação científica e tecnológica e à inovação. Emenda Constitucional n. 85, de 26 de fevereiro de 2015. Diário Oficial (da) República Federativa do Brasil, Brasília, DF, 11 jan. 2016a. Disponível em: http://www.planalto.gov.br/ccivil_03/_Ato2015-2018/2016/Lei/ L13243.htm\#art2. Acesso em: 5 jul. 2019.

BRASIL. Decreto n. 8.772, de 11 de maio de 2016. Regulamenta a Lei n. 13.123, de 20 de maio de 2015, que dispõe sobre o acesso ao patrimônio genético, sobre a proteção e o acesso ao conhecimento tradicional associado e sobre a repartição de benefícios para conservação e uso sustentável da biodiversidade. Diário Oficial [da] União, Brasília, DF, 12 de maio de 2016b. p. 1, Seção 1. Disponível em: https:/www.planalto.gov.br/ccivil_03/_ato2015-2018/2016/decreto/d8772. htm. Acesso em: 7 jul. 2019.

BRASIL. Decreto n. 9.273, de 7 de fevereiro de 2018. Disponível em: http://www.planalto.gov.br/ ccivil_03/_Ato2015-2018/2018/Decreto/D9283.htm. Acesso em: 9 mar. 2020.

CAMPOS, A. C. de; CALLEFI, P.; MARCON, A. P. P. O Brasil no contexto mundial da inovação tecnológica. Pesquisa \& Debate, [S.1.], v. 20, n. 1, p. 73-96, 2009. Disponível em: https://revistas. pucsp.br/rpe/article/viewFile/7536/5489. Acesso em: 17 jul. 2019.

CAPDEVILLE, G. de; ALVES, A. A.; BRASIL, B. dos S. A. F. Modelo de inovação e negócios da Embrapa Agroenergia: gestão estratégica integrada de P\&D e TT. Brasília, DF: Embrapa Agroenergia, 2017. 73p. (Embrapa Agroenergia. Documentos, 24). Disponível em: http://ainfo. cnptia.embrapa.br/digital/bitstream/item/173992/1/DOC-24-CNPAE.pdf. Acesso em: 5 jul. 2019.

CAVALCANTI, A. R. Modelo conceitual para transferência de tecnologia na Embrapa: um esboço. Brasília, DF: Embrapa, 2015. 120p. (Embrapa-DPD. Texto para discussão, n. 44). Disponível em: http://ainfo.cnptia.embrapa.br/digital/bitstream/item/131928/1/TEXTO-DISCUSSAO-44ed01-2015.pdf. Acesso em: 22 jun. 2019.

EMBRAPA. Missão, visão e valores. [2019]. Disponível em: https://www.embrapa. br/missao-visaoe-valores. Acesso em: 22 jun. 2019.

EMBRAPA. Visão 2030: o futuro da agricultura brasileira. Brasília, DF, 2018. 212 p. il. color. Disponível em: https://www.embrapa.br/documents/10180/9543845/Vis\%C3\%A3o+2030+-+o+fut uro +da + agricultura + brasileira/2a9a0f27-0ead-991a-8cbf-af8e89d62829?version=1.1. Acesso em 5 jul. 2019.

FERNANDES, R. F. et al. Práticas de Transferência de Tecnologia: uma análise multicascos.

Cadernos de Prospecção, Salvador, Ed. Esp. VIII ProspeCT\&I, v. 11, n. 5, p. 1.342-

1.359, dez. 2018. Disponível em: https://portalseer.ufba.br/index.php/nit/article/view/27316/

PR\%C3\%81TICAS\%20DE\%20TRANSFER\%C3\%8ANCIA\%20DE\%20TECNOLOGIA\%3A\%20

UMA\%20AN\%C3\%81LISE\%20MULTICASOS. Acesso em: 5 jul. 2019. 
FUCK, M. P.; VILHA, A. M. Inovação Tecnológica: da definição à ação. Contemporâneos -

Revista de Artes e Humanidades, [S.1.], n. 9, p. 1-21, nov.-abr. 2011-2012. Disponível em: http:// revistacontemporaneos.com.br/n9/dossie/inovacao-tecnologica.pdf. Acesso em: 5 jul. 2019.

GIL, A. C. Como elaborar projetos de pesquisa. 4. ed. São Paulo: Atlas, 2002. 176p. Disponível em: https://professores.faccat.br/moodle/pluginfile.php/13410/mod_resource/content/1/como_ elaborar_projeto_de_pesquisa_-_antonio_carlos_gil.pdf. Acesso em: 22 jun. 2019.

MANOS, M. G. L. et al. (ed.). Paz, justiça e instituições eficazes: contribuições da Embrapa. Brasília, DF: Embrapa, 2018. cap. 5. E-book. (Objetivos de Desenvolvimento Sustentável, 16). Disponível em: https://ainfo.cnptia.embrapa.br/digital/bitstream/item/191886/1/Governaca.pdf. Acesso em: 6 jul. 2019.

MARCONI, M. A.; LAKATOS, E. M. Fundamentos da Metodologia Científica. 5. ed. São Paulo: Atlas, 2003. 315 p. Disponível em: https://docente.ifrn.edu.br/olivianeta/disciplinas/copy_of_ historia-i/historia-ii/china-e-india. Acesso em: 22 jun. 2019.

MORGADO, E. M. Inovação, novos conceitos ampliados: novas oportunidades para as empresas. Revista de Ciências Gerenciais, [S.l.], v. 15, n. 21, p. 225-235, 2011. Disponível em: http:// revista.pgsskroton.com.br/index.php/rcger/article/viewFile/2248/2148. Acesso em: 5 jul. 2019.

RIBEIRO, P. V. V. Inovação Tecnológica e Transferência de Tecnologia. Brasília, DF: MCT, 2001. 38p. Disponível em: http://bibliotecadigital.puc-campinas.edu.br/services/e-books-MS/2212.pdf. Acesso em: 6 jul. 2019.

ROMAN, V. B.; LOPES, M. T. de P. Importância da Transferência de Tecnologia realizada nas universidades brasileiras para a alavancagem da competitividade do país no cenário econômico mundial. Iberoamerican Journal of Industrial Engineering, [S.1.], v. 4, n. 8, p. 111-124, 2012. Disponível em: http://incubadora.periodicos.ufsc.br/index.php/IJIE/article/view/2089/pdf. Acesso em: 17 jul. 2019.

ROSA, J. P.; ROSA, S. S. da; ANTONIOLLI, P. D. A estratégia da inovação, a chave para o desenvolvimento: uma comparação entre a realidade brasileira e americana. Iberoamerican Journal of Industrial Engineering, v. 10, n.19, p. 157-176, 2018. Disponível em: http:// incubadora.periodicos.ufsc.br/index.php/IJIE/article/view/v10n1901/pdf. Acesso em: 17 jul. 2019.

SANTOS, W. M. S. et al. Agricultura Digital: softwares e serviços web disponibilizados pela Embrapa para o agronegócio brasileiro. In: MOSTRA DE ESTAGIÁRIOS E BOLSISTAS DA EMBRAPA INFORMÁTICA AGROPECUÁRIA, 14., 2018, Campinas. Resumos expandidos [...] Brasília, DF: Embrapa, 2018. p. 82-87. (Embrapa Informática Agropecuária. Eventos técnicos \& científicos, 1). Disponível em: https:/ainfo.cnptia.embrapa.br/digital/bitstream/item/188302/1/Mostra-2018-82-87. pdf. Acesso em: 5 jul. 2019.

SCHUMPETER, J. A. A teoria do desenvolvimento econômico: uma investigação sobre lucros, capital, crédito, juro e o ciclo econômico. Tradução de Maria Sílvia Possas. São Paulo: Nova Cultural, 1988. Disponível em: http://www.ufjf.br/oliveira_junior/files/2009/06/s_Schumpeter_-_Teoria_do_ Desenvolvimento_Econ\%C3\%B4mico_-_Uma_Investiga\%C3\%A7\%C3\%A3o_sobre_Lucros_Capital_ Cr\%C3\%A9dito_Juro_e_Ciclo_Econ\%C3\%B4mico.pdf. Acesso em: 5 jul. 2019.

SILVA NETTO, G. P. da; OLIVEIRA, D. R. M. dos S. Sistema de Gestão das Soluções Tecnológicas da Embrapa - Gestec. In: MOSTRA DE ESTAGIÁRIOS E BOLSISTAS DA EMBRAPA 
INFORMÁTICA AGROPECUÁRIA, 10., 2014, Campinas. Resumos [...], Brasília, DF: Embrapa, 2014. p. 128-130. Disponível em: http://ainfo.cnptia.embrapa.br/digital/bitstream/item/118648/1/ Resumos-sistemadegestao.pdf. Acesso em: 6 jul. 2019.

SOUZA, A. P.; RODRIGUES, G. Transferência de Tecnologia. Jusbrasil Artigos, 2016. Disponível em: https://anapsouzza.jusbrasil.com.br/artigos/325808308/transferencia-de-tecnologia. Acesso em: 8 jul. 2019.

TURAZI, C. M. V. et al. GESTEC Manual: módulo qualificação dos ativos tecnológicos e prétecnológicos. Brasília, DF: Secretaria de Inovação e Negócios, 2018. 51p.

YIN, R. K. Estudo de caso: planejamento e métodos. Tradução de Daniel Grassi. 2. ed. Porto Alegre: Bookman, 2001. 200p. Disponível em: https://saudeglobaldotorg1.files.wordpress.

com/2014/02/yin-metodologia_da_pesquisa_estudo_de_caso_yin.pdf. Acesso em: 10 jul. 2019.

\section{Sobre os Autores}

\section{Adelina do Socorro Serrão Belém}

E-mail: adelina.belem@embrapa.br

Mestranda em Propriedade Intelectual e Transferência de Tecnologia para a Inovação pelo PROFNIT/UNIFAP.

Endereço profissional: Rodovia Juscelino Kubitschek, n. 2.600, km 5, Universidade, Macapá, AP. CEP: 68903-419.

\section{Jesusa Vania Bagundes Nascimento}

E-mail: vbagundes@yahoo.com.br

Mestranda em Propriedade Intelectual e Transferência de Tecnologia para a Inovação pelo PROFNIT/UNIFAP.

Endereço profissional: Rodovia Juscelino Kubitschek, km 2, Jardim Marco Zero, Macapá, AP. CEP: 68903-419.

\section{Claudio Márcio Campos de Mendonça}

E-mail:cmarcio@gmail.com

Doutor em Administração.

Endereço profissional: Rodovia Juscelino Kubitschek, km 2, Jardim Marco Zero, Macapá, AP. CEP: 68903-419. 